\title{
Application of BP Neural Network Model in the Recycled Concrete Performance Prediction
}

\author{
Jing-gan Shao ${ }^{1, \mathrm{a}}$, Xiao-xiang $\mathrm{Ji}^{2, \mathrm{~b}}$ and $\mathrm{Ran} \mathrm{Li}^{2, \mathrm{c}}$
}

1. Henan Vocational and Technical College of Communications, Zhengzhou 450000, Henan, China;

2. Henan Institute of Highway Engineering Technology Co., Ltd, Zhengzhou 450000, Henan, China

aEmail: docling@126.com

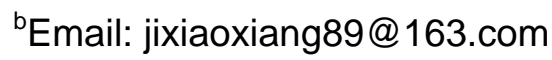

cEmail: seeseay@126.com

\begin{abstract}
Keywords: Road Engineering; Construction Wastes; Recycled Concrete; BP Neural Network; Concrete Performance; Prediction

Abstract: When the construction wastes were used as raw materials of Recycled concrete, the type and replacement ratio of recycled aggregates should be considered in addition to mix proportion. It is very difficult to describe the complicated nonlinear relationship between different indexes. Through analyzing design process of BP neural network model, the appropriate network parameters were selected, the BP neural network model about performance of recycled concrete is established. After the BP neural network was trained, the 7-20-3 BP neural network model is established to realize nonlinear mapping about performance of recycled concrete. The results show that the established BP network model can accurately predict the recycled concrete slump, 28d compressive strength and elastic modulus, which has a good applicability to the concrete.
\end{abstract}

\section{Instruction}

Every year to billion tons of construction wastes in our country were produce, it is very difficult to handle. Through screening and crushing the waste brick and concrete in the construction waste, the recycled aggregate was produced which can replaced natural aggregate to produce recycled concrete, and it can solved the problems of the construction waste. Domestic and foreign scholars have done a lot of experimental study on the basic properties of recycled concrete, but the source of the recycled aggregates, crushing technology, physical properties are different. In addition to mix proportion, the physical properties of recycled aggregate which include apparent density, bulk density, water absorption and crushing index and replacement ratio of recycled aggregates must be considered. So we need a kind of intelligent analysis tool to realize the recycled concrete strength and working performance and mixture ratio, and the nonlinear mapping between classification of recycled aggregate performance.

Artificial neural network theory regards biological neural network as the prototype, analyzing the microstructure, imitating the running mechanism of the biological neural networks, then the numerical calculation model is got which can solve the complex nonlinear relationship between simple input signals. This paper uses the BP neural network model to realize the study on the properties of recycled concrete, the non-linear relation between recycled concrete working performance and various influencing factors was build. And the BP network model is adopted to the practical application to make a prediction of the recycled concrete slump, 28d compressive strength and elastic modulus and verify the applicability of the model.

\section{Setting of BP Neural Network Parameters}

\subsection{Selection the network structure}

Many factors affecting the performance of recycled concrete, such as water cement ratio, sand ratio, types and replacement ratio of recycled aggregate, and cement varieties and dosage, additive, etc. When the network model is established, because the test conditions, partly due to the limitations 
and the network structure of data acquisition, it is necessary to find out the main factors. Based on engineering practice, the recycled aggregate apparent density, water absorption and crush index, the dosage of cement, water cement ratio, sand ratio, ratio of recycled coarse aggregate content were selected as input parameters of BP neural, and the concrete slump, 28d compressive strength, elastic modulus were selected as the output parameters.

\subsection{Network parameters setting and initialization of the network weights}

The transfer functions of BP neural network model are linear function and S function, both of them must be continuous and derived function. Logsig function is S logarithmic function, the tansig function is hyperbolic tangent $S$ transfer function. After normalization treatment, the training sample data in this paper is in [0.2, 0.8], means that both two transfer function can be used. To determine the optimal selection of transfer function combination, comprehensive comparison should be made between any two kinds of function composition of BP neural network, include the input layer and hidden layer, hidden layer and output layer.

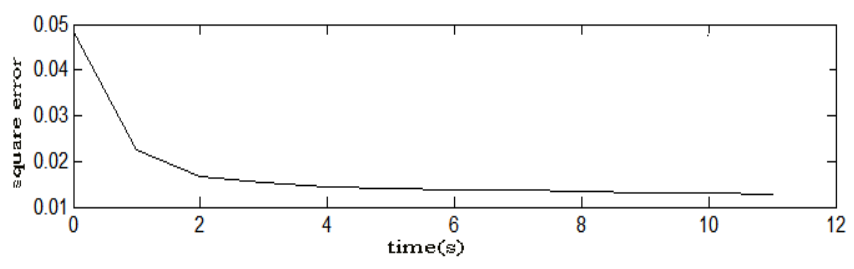

(a) logsig-logsig function

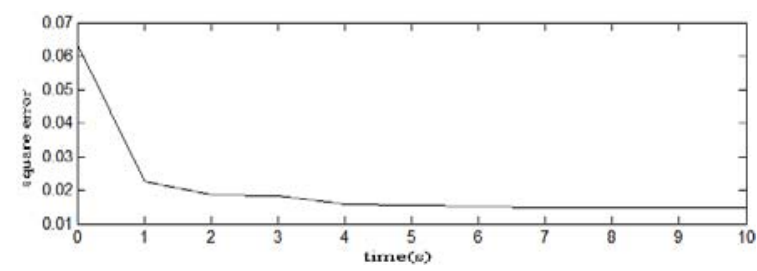

(c) ansig-logsig function

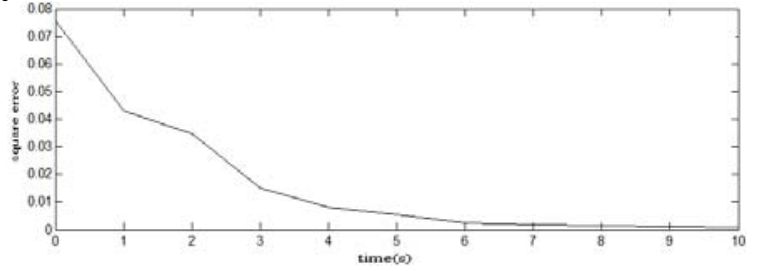

(b) tansig-tansig function

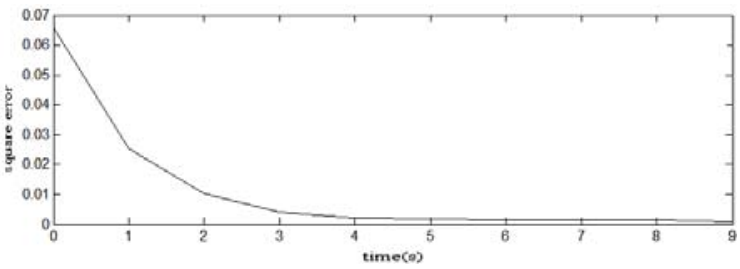

(d) logsig-tansig function

Fig.1 Error curves of different function combination

Comparing the four kinds of composition functions in figure 1, BP neural networks with the function of logsig-logsig and tansig-logsig didn’t convergence to 0.001 in the end, means that the network performance is poor. Tansig-tansig combination convergence error can meet the requirements, but the network convergence speed is lower than logsig-tansig combination. After comprehensive consideration, logsig function was used as the transfer function between input layer and hidden layer and the tansig function was used between the hidden layer and output layer.

Network training algorithm is the most important aspect of network building, Levengerg-Marquardt training method of the training function of trainlm has advantages of convergence speed is faster, shorter training time and high precision after comparing a large number of related information. The parameters set using trainlm training function are shown in table 1.

Tab.1 Default parameters of Trainlm training function

\begin{tabular}{ccc}
\hline parameters & default values & properties \\
\hline net.trainParam.epochs & 1000 & Number of training. maximum is 1000 \\
net.trainParam.showWindow & 25 & Training steps between two shows. no display \\
net.trainParam.goal & 0 & Set to NaNa \\
net.trainParam.time & inf & Training goal \\
net.trainParam.min_grad & le-7 time, inf means unlimited time \\
net.trainParam.min_fail & 6 & Minimum performance gradient \\
\hline
\end{tabular}




\section{Training of BP Neural Network Model}

\subsection{Established of BP neural network model for recycled concrete performance}

The input layer of BP neural network model established is $7 \times 49$ vector group which represented by $\mathrm{P}$ and output layer is $3 \times 49$ vector group represented by $\mathrm{T}$. The network structure is $7-20-3$, trainlm function was used as network training function. Logsig function became the transfer function between input layer and hidden layer, and tansig function was used between the hidden layer and output layer. After the network parameters were set, the BP neural network model of recycled concrete performance started to train. BP neural network model is shown in figure 2.

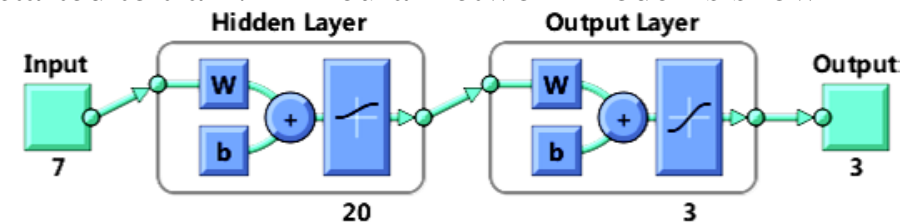

Fig.2 BP neural network model for recycled concrete performance

The basic parameters of BP neural network model for recycled concrete performance are set as following: largest training number is 100 , sum of squares objective error is 0.001 , the minimum gradient is $1 \mathrm{e}^{-7}$, the maximum of failure is 6 , and other parameters are the default values in the Matlab neural network toolbox. The neural network weights and threshold of each layer must be initialized before training, the least is regarded as initial weight and threshold. the running time of structure of 7-20-3 for BP neural network model is 2 s, and the convergent of the training sample data set reaches expected error range when the iteration time is 10 . The mean square error is 0.000998 , then the error didn't reduce, and the training is stopped.

\subsection{Operation result error of BP neural network}

The operation result error performance of BP neural network reflects the error change trend of training sample, test sample and test sample, as shown in figure 3. Network training error was reducing in the process of training and network error drops fastest when training steps was 3-6, which indicate that the network structure and parameters setting is reasonable instead of trapping in local minima. The mean square error reached the minimal 0.0038549 which is in the optimal prediction range when the step of validation in the training sample was 6.

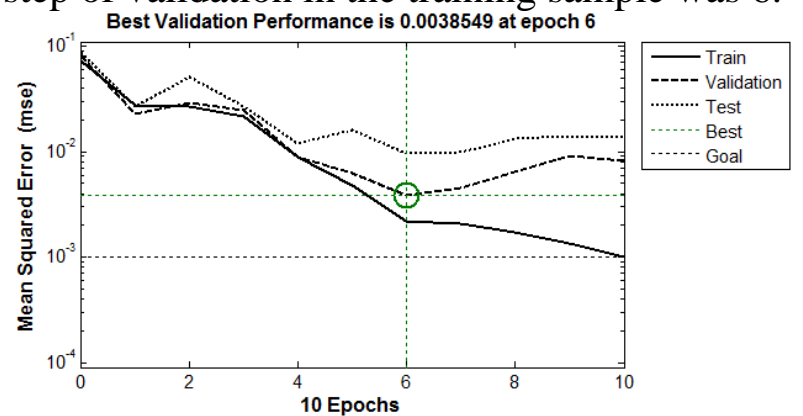

Fig.3 Operation result error performance of BP neural network

\subsection{Correlation between predicted and actual values}

The distribution and correlation of test and estimated values of training sample, validation, sample and test sample are shown in figure 4. After linear regression analysis of network output and the expected output, the sample data correlation index $\mathrm{R}$ close to 1 , indicates that the network sample data after training and the actual value is consistent, has reached the expected goal. 

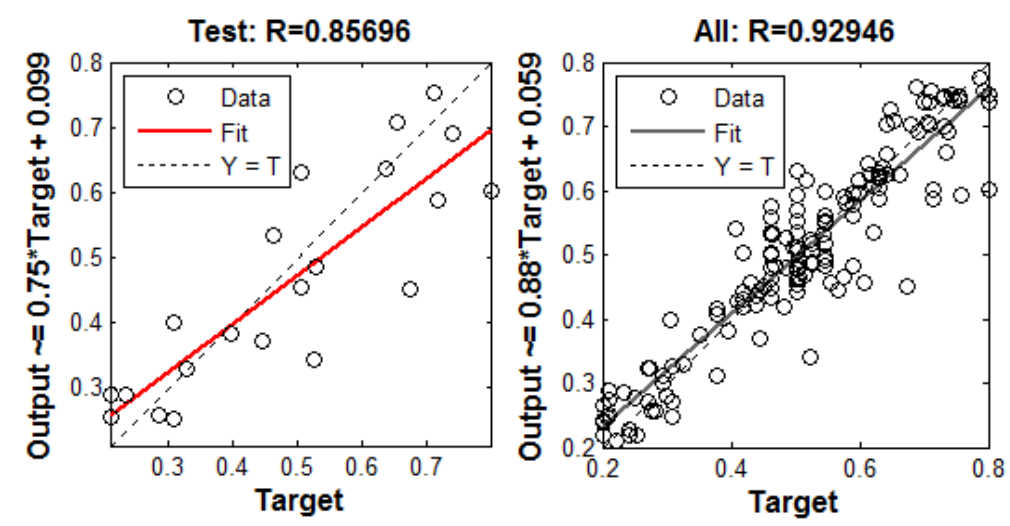

Fig.4 Linear correlation of actual and estimated values

\section{Application of BP Neural Network Model}

4.1 Build the BP neural network and detect the sample database

The recycled aggregate used came from Pingdingshan xulong renewable resources co., LTD., and the size range was 0 to $25 \mathrm{~mm}$. the recycled aggregate was composed of waste brick, waste mortar and broken glass produced by demolishiing brick structure. The apparent density, water absorption and crushing index of recycled coarse aggregate and natural gravel are shown in table 2.

Based on the test, Test sample includes 15 groups of different mixing ratio of recycled aggregate concrete, and concrete mixture slump of each group must be measured. Then 45 pieces of test cube $(150 \mathrm{~mm} \times 150 \mathrm{~mm} \times 150 \mathrm{~mm})$ and 90 pieces of prism block $(150 \mathrm{~mm} \times 150 \mathrm{~mm} \times 150 \mathrm{~mm})$ should be made to measure the $28 \mathrm{~d}$ compressive strength and elastic modulus.

Tab.2 Physical properties of Recycled aggregate and natural gravel

\begin{tabular}{cccc}
\hline & apparent density $\left(\mathrm{kg} / \mathrm{m}^{3}\right)$ & crushing index & Bibulous rate \\
\hline Recycled aggregate & 2177 & 33.4 & 15.5 \\
natural gravel & 2780 & 9 & 0.6 \\
\hline
\end{tabular}

In accordance with the relevant specification of test, the resulting test sample test data are shown in table 3.

Tab.3 Test sample of recycled aggregate concrete

\begin{tabular}{cccccccc}
\hline Number & $\begin{array}{c}\text { Cement } \\
\text { content } \\
k g / m^{3}\end{array}$ & Sand ratio & $\begin{array}{c}\text { recycled aggregate } \\
\text { replacement rate } \\
\%\end{array}$ & $\begin{array}{c}\text { water } \\
\text { cement ratio }\end{array}$ & $\begin{array}{c}\text { concrete } \\
\text { slump } \\
\mathrm{mm}\end{array}$ & $\begin{array}{c}\text { compressive } \\
\text { strength } \\
M P a\end{array}$ & $\begin{array}{c}\text { elastic } \\
\text { modulus } G P a\end{array}$ \\
\hline 1 & 380 & $36 \%$ & 0 & 0.6 & 50 & 38.3 & 30.3 \\
2 & 380 & $36 \%$ & 30 & 0.6 & 20 & 37.5 & 20.4 \\
3 & 380 & $36 \%$ & 50 & 0.6 & 15 & 41.7 & 24.7 \\
4 & 380 & $36 \%$ & 70 & 0.6 & 10 & 36.8 & 18.8 \\
5 & 380 & $36 \%$ & 100 & 0.6 & 25 & 34.5 & 15.8 \\
6 & 345 & $33 \%$ & 0 & 0.58 & 45 & 28.7 & 24.5 \\
7 & 345 & $33 \%$ & 30 & 0.58 & 60 & 27.5 & 23.3 \\
8 & 345 & $33 \%$ & 50 & 0.58 & 50 & 24.6 & 22.6 \\
9 & 345 & $33 \%$ & 70 & 0.58 & 80 & 24.9 & 23.8 \\
10 & 345 & $33 \%$ & 100 & 0.58 & 50 & 24.5 & 14.3 \\
11 & 408 & $34 \%$ & 0 & 0.49 & 50 & 39.9 & 26.5 \\
12 & 408 & $34 \%$ & 30 & 0.49 & 70 & 28.9 & 23.9
\end{tabular}




\begin{tabular}{cccccccc}
\hline Number & $\begin{array}{c}\text { Cement } \\
\text { content } \\
\mathrm{kg} / \mathrm{m}^{3}\end{array}$ & Sand ratio & $\begin{array}{c}\text { recycled aggregate } \\
\text { replacement rate } \\
\%\end{array}$ & $\begin{array}{c}\text { water } \\
\text { cement ratio }\end{array}$ & $\begin{array}{c}\text { concrete } \\
\text { slump } \\
\mathrm{mm}\end{array}$ & $\begin{array}{c}\text { compressive } \\
\text { strength } \\
\mathrm{MPa}\end{array}$ & $\begin{array}{c}\text { elastic } \\
\text { modulus } \mathrm{GPa}\end{array}$ \\
\hline 13 & 408 & $34 \%$ & 50 & 0.49 & 60 & 27.7 & 21.3 \\
14 & 408 & $34 \%$ & 70 & 0.49 & 60 & 27.5 & 16.5 \\
15 & 408 & $34 \%$ & 100 & 0.49 & 55 & 24.9 & 14.5 \\
\hline
\end{tabular}

\subsection{Performance evaluation of BP neural network}

The 15 set of test data in table 3 was used to test the trained BP neural network model: the input variable such as dosage of cement, sand ratio, water cement ratio and recycled aggregate content ratio of the recycled aggregate concrete test sample should be normalized. The normalized formula was $X^{\prime}=0.2+\frac{0.6\left(X-X_{\min }\right)}{X_{\max }-X_{\min }}$. Then the test data after normalization was substituted in the trained BP neural network, the simulation results of recycled aggregate concrete were got, such as slump, 28d compressive strength and elastic modulus. The predicted results are shown in table 4.

Tab.4 Prediction results of recycled aggregate concrete with BP neural network

\begin{tabular}{cccccccccc}
\hline & \multicolumn{3}{c}{ slump } & \multicolumn{4}{c}{ compressive strength } & \multicolumn{3}{c}{ elastic modulus } \\
\hline \multirow{2}{*}{ Number } & $\begin{array}{c}\text { Measured } \\
\text { values }\end{array}$ & $\begin{array}{c}\text { Predictive } \\
\text { values }\end{array}$ & $\begin{array}{c}\text { Relative } \\
\text { error }\end{array}$ & $\begin{array}{c}\text { Measured } \\
\text { values }\end{array}$ & $\begin{array}{c}\text { Predictive } \\
\text { values }\end{array}$ & $\begin{array}{c}\text { Relative } \\
\text { error }\end{array}$ & $\begin{array}{c}\text { Measured } \\
\text { values }\end{array}$ & $\begin{array}{c}\text { Predictive } \\
\text { values }\end{array}$ & $\begin{array}{c}\text { Relative } \\
\text { error }\end{array}$ \\
\hline 1 & 50 & 46 & $-8.00 \%$ & 38.3 & 36.4 & $-5.00 \%$ & 30.3 & 32.2 & $6.30 \%$ \\
2 & 20 & 21 & $5.00 \%$ & 37.5 & 35.6 & $-5.10 \%$ & 20.4 & 22.1 & $8.30 \%$ \\
3 & 15 & 14 & $-6.70 \%$ & 41.7 & 45.1 & $2.70 \%$ & 24.7 & 25.6 & $3.60 \%$ \\
4 & 10 & 9 & $10.00 \%$ & 36.8 & 38.8 & $4.10 \%$ & 18.8 & 20.2 & $7.40 \%$ \\
5 & 25 & 23 & $8.00 \%$ & 34.5 & 37.3 & $7.50 \%$ & 15.8 & 14.7 & $-7.00 \%$ \\
6 & 45 & 42 & $-6.70 \%$ & 28.7 & 30.4 & $5.90 \%$ & 24.5 & 23.8 & $-2.90 \%$ \\
7 & 60 & 59 & $-1.70 \%$ & 27.5 & 29.8 & $8.40 \%$ & 23.3 & 24.6 & $5.60 \%$ \\
8 & 50 & 48 & $-4.00 \%$ & 24.6 & 26.7 & $8.50 \%$ & 22.6 & 24.9 & $10.20 \%$ \\
9 & 80 & 75 & $-6.30 \%$ & 24.9 & 23.5 & $-5.60 \%$ & 23.8 & 22.5 & $-5.50 \%$ \\
10 & 50 & 48 & $-4.00 \%$ & 24.5 & 26.2 & $6.90 \%$ & 14.3 & 14.9 & $4.20 \%$ \\
11 & 50 & 52 & $4.00 \%$ & 39.9 & 41.6 & $4.30 \%$ & 26.5 & 28.4 & $7.20 \%$ \\
12 & 70 & 74 & $5.70 \%$ & 28.9 & 30.4 & $5.20 \%$ & 23.9 & 25.6 & $7.10 \%$ \\
13 & 60 & 63 & $5.00 \%$ & 27.7 & 28.6 & $3.20 \%$ & 21.3 & 22.5 & $5.60 \%$ \\
14 & 60 & 64 & $6.70 \%$ & 27.5 & 26.4 & $-4.00 \%$ & 16.5 & 15.2 & $-7.90 \%$ \\
15 & 55 & 58 & $5.50 \%$ & 24.9 & 26.2 & $5.20 \%$ & 14.5 & 15.8 & $9.00 \%$ \\
\hline
\end{tabular}

Note: relative error $=$ (predicted value - measured values)/measured values

The average relative error of the prediction precision about the slump, compressive strength and elastic modulus are 5.81\%, 5.44\% and 5.81\%. Table 4 indicates that the establishment of BP neural network model for recycled aggregate concrete performance with the structure of 7-20-3 has a higher prediction accuracy. The error of Some test sample is great and discrete, so the reliability of the collected sample data has a great influence on the prediction precision of the BP network. To further improve the stability of the BP neural network prediction, more reliable sample data need to collect.

\section{Conclusion}

After analyzing basic properties of recycled concrete such as apparent density, water absorption and crush index, recycled coarse aggregate replacement ratio, water cement ratio and other factors, the 
article selected the appropriate network parameters and established a BP neural network model by using artificial neural network theory. The BP neural network model took slump, 28d compressive strength and elastic modulus as the output parameters, which was verified by testing. The conclusion is as follows:

(1) The article established a BP neural network model with the structure of 7-20-3, which selected the apparent density, water absorption and crush index, the dosage of cement, water cement ratio, sand ratio, ratio of recycled aggregate content as input parameters and took slump, $28 \mathrm{~d}$ compressive strength, elastic modulus as the output parameters.

(2) Process of training BP neural network model established run quickly, and the convergent of the training sample data set reaches expected error range when the iteration time is 10 . The mean square error is 0.000998 means that the model and parameter setting was quite reasonable.

(3) The average relative error of the prediction precision about the slump, compressive strength and elastic modulus are 5.81\%, 5.44\% and 5.81\%. The result shows that the model has a good prediction accuracy, indicates that the BP neural network has good applicability.

\section{References}

[1] Jianzhuang XIAO. Recycled Concrete[M], Beijing: China Architecture \& Building Press, 2008.(in Chinese)

[2] Yuedong SUN, Jianzhuang XIAO. Aggregate of recycled concrete[J], Concrete, 2004, (6), 33-36. (in Chinese)

[3] Sheng YU. Study on Relationship Between Pore Structure and Strength of Concrete Based on Artificial Neural Networks[D]. Hangzhou: Zhejiang University, 2006(in Chinese)

[4] C.J.Kibert. Concrete/Masonry Recycling Progress in the USA[C].Demolition and Reuse of Concrete and Masonry. New York: F\&FN Spon, 1994. (in Chinese)

[5] T.Noguchi,M. Tamura. Concrete Design towards Complete Recycling. Structural Concrete, 2001(3): 155-167.

[6] Zhiyuan YANG. Prediction model of common concrete strength by BP artificial neural network[J]. Journal of Chang'a n University (Natural Science Edition), 2003, V23(3): 50-52(in Chinese)

[7] LI Ruige, Yang Guoli. Optim izing m ixture ratio design m ethod of regenerated concrete based on Artificial Neural Networks[J]. Concrete, 2009, (7): 117-122(in Chinese) 